\title{
Day of the Week Effect of Stock Returns: Empirical Evidence from Colombo Stock Exchange
}

\author{
S C THUSHARA \\ Lecturer, Department of Commerce and Financial Management, Faculty of Commerce and \\ Management Studies,Univeristy of Kelaniya, Kelaniya, Sri Lanka \\ scthushara@kln.ac.lk \\ PRABATH PERERA \\ Assistant Lecturer, Department of Accountancy, Faculty of Commerce and Management \\ Studies,Univeristy of Kelaniya, Kelaniya, Sri Lanka \\ prabathperera@yahoo.com
}

\begin{abstract}
Many empirical studies have been carried out both in the developed and developing economies to test the presence of anomalies in stock returns and volatility. The most commonly tested seasonal anomalies are day of the week effect, month of the year effect, holiday effect, Monday effect and Friday effect. Previous studies strongly support the existence of seasonal anomalies. Existence of seasonal anomalies let the investors to earn abnormal returns by trading on past information. This study attempts to test whether the day of the week effect is present in the stock returns of the Colombo Stock Exchange. For this purpose, stock returns based on ASPI for the period of 2002 to 2011 with 2390 observation are taken into account. The day of the week effect hypothesis is tested using both OLS model and GARCH $(1,1)$ model. The research provides strong evidence to support the day of the week effect. Furthermore, there is a Thursday, Wednesday and Friday effect in the stock returns. Thus, investors can earn abnormal returns by trading on a strategy based on past information. It is recommended to buy stock on Mondays and Tuesdays and sell them on Wednesdays, Thursdays and Fridays to earn abnormal returns.
\end{abstract}

Key words: Day of the week effect, Stock returns, GARCH, Colombo Stock Exchange, Stock market Anomalies 


\section{Introduction}

The topic of capital market efficiency is one of the most searched areas in finance and the importance of the capital market efficiency has increased in last few decades, due to different types of capital market behaviors and investment habits of the investors in all over the world. Number of studies has been conducted to test this capital market efficiency or the efficient market hypothesis (EMH), and recently researches have collected evidence against the EMH.

One of the significant anomalies of EMH is the seasonal effect. Seasonal anomalies are reported by researches for developed as well as emerging stock markets. But, most of the studies were conducted on developed countries. The most common seasonal anomalies are the Day of the week effect, Day of the month effect and the month of the year effect (the January effect). According to past empirical studies Day of the week is the most talked anomaly among those.

The existence of the seasonal effect implies market inefficiency. If the seasonal effects are well-known and systematic in the stock markets, then investors can have useful clues regarding their investment decisions. It is important to know whether there are variations in volatility of stock returns by day of the week patterns, week of the month patterns or the month of the year pattern and whether a high/low return is associated with a corresponding high/low return for a given day, week or month. So, if investors have this knowledge they can adjust their portfolios by considering these variations in the stock returns. Hakan Berument and Hail Kiyamaz (2001), state the usefulness of finding certain patterns in volatility, including the use of predicted volatility patterns in hedging and speculative purposes and use of predicted volatility in valuation of certain assets specifically stock index options.

Sri Lankan stock market, (known as the Colombo Stock Exchange) is considered as one of the emerging stock markets in the world. But still it is not efficient in the weak form. So, that implies the anomalies in stock returns may present in the market. That may lead investors to earn abnormal returns by trading on past information. Literature for the past decades has been documented on this issue in several occasions in Sri Lanka

This study seeks to test whether the day of the week effect exists in the Colombo Stock Exchange. Substantial differences are present in the Colombo Stock Exchange when compared to the stock markets of developed countries. After ending of the North and East 
civil war, capital flows are taking place on a massive scale to Sri Lanka, in order to grab new opportunities, especially in new market areas in the country. Most of the investors, especially international investors are more concerned with the market efficiency. The main purpose of this study is to provide some assistance to investors to formulate profitable trading strategies by predicting the share price behaviors with the information of these anomalies.

Findings of this study will help both Sri Lankan and international investors to make profitable investment strategies and to plan their investment portfolios. That is the major contribution of this study. And the findings of the study will also help future researchers, as well as the decision makers of the country in many ways.

\section{Literature Review}

The Efficient Market hypothesis (EMH) states that, if a market is efficient then prices at any time fully reflect all available information (Philpott and Firer, 1995). There are three forms of the EMH: 1) Weak form (Predictability) 2) Semi-strong form (Event studies) and 3) Strong form (Inside information) (Fama, 1991). According to Philpott and Firer (1995), a share price anomaly occurs, where there is a significant deviation from the exact theoretical relationship between two related shares. So that, investors can earn abnormal returns by using a trading strategy based on past information (Bepari and Mollik, 2009). Researchers have conducted number of studies to test different types of stock market anomalies to the EMH. Among such anomalies, the size effect and the seasonal effect are seen as the most important patterns and have been extensively studied and documented in the literature for the last few decades.

\section{The Seasonal Effect}

Empirical studies have turned up a wide range of anomalies relating to seasonality in stock returns. (Balbina and Martins, 2002, Fernando and Pathirawasam, 2006, Thilakerathne et al., 2007).The most common of these anomalies appear to be weekend effect or the Day of the Week effect, where stocks exhibit significantly lower returns over the period between Friday's close and Monday's close (Berument and Kiymaz, 2001, Selvakumar, 2011). A January effect, where returns are unusually high during the month of January as compared to any other month (Selvakumar, 2011, Bepari and Mollik, 2009 ) And a Holiday effect, where returns are much higher on trading days immediately prior to holidays (Balbina and Martins,2002 ). 


\section{Day of the Week Effect on Stock Returns}

There is an extensive literature on day of the week effect for the stock returns. According to Syed A. Basher and Perry Sadorsky (2006), investors could buy stocks on days with abnormally low returns and sell stocks on days with abnormally high returns. The day of the week effects are present both developed and emerging stock markets.

The existence of the day of the week effect on stock returns is primarily reported for the U.S. stock market (French 1980). French (1980) studied the S \& P 500 index for the period of 1953-1977 and his findings indicate that the mean returns on Friday is higher than the mean return on Monday. This form of calendar anomaly is not limited to US equity markets but there are several other studies in North America also attempted to explain the Monday effect. A daily seasonal anomaly is found in the Canadian stock market with a negative Monday and positive Friday effect (Berument and Kiymaz, 2001). Day of the week effect is also documented for other stock markets around the world, especially for the Europe and the Pacific Rim region. A significant negative Monday effect is reported for the U.K., Germany, France, and Switzerland, and a significant positive Friday effect is observed in France (Jaffe and Westerfield, 1985; Kiymaz and Berument, 2003)). In addition, a significant negative mean return on Tuesday is reported for the U.K. Germany, France, Austria and the Netherlands (Jaffe and Westerfield, 1985). Moreover, a negative Friday effect is abnormally identified for Germany and Austria (Balaban et al., 2001).

Further Rosa et al., (2006), used series of daily returns for the period of 1997 to 2004, from the corresponding stock indices of the following European markets: Germany, Austria, Belgium, Denmark, Spain, France, The Netherlands, Italy, Portugal, The United Kingdom, The Czech Republic, Sweden and Switzerland. According to their findings, the day of the week effect is present in all of the financial markets except in Portugal and the Czech Republic, where a symmetric model is applied.

The day of the week in the Pacific Rim region is observed by several researches (Jaffe and Westerfield, 1985; Dubois and Louvet, 1996). They found that the highest mean return is observed on Friday; while the lowest mean return occur on Tuesday for both the Japanese and Australian stock markets. Jaffe and Westerfield (1985) indicated that, time-zone differences between such markets and the US market might account for the presence of the negative Tuesday effect. 
In the most recent period, Kohers et al., (2004) find that the day-of-the-week effect has disappeared in most developed stock markets. Specifically, they document that the daily seasonal anomaly is observed in the U.S., Japan, the U.K., France, Germany, Canada, Italy, the Netherlands, Switzerland, and Australia for the period from 1980 to 1990, but conversely it is no longer in all markets, except Japan, during the period between 1991 and 2002. These findings indicate that long-term improvements in market efficiency would have diminished the day-of-the-week effect on stock returns (Truong, 2012).

Turning to emerging markets, Wong et al., (1992) tested the difference in mean returns across days of the week in the stock market indexes of five Asian countries for the period 1975-1988. They found a significantly negative Monday effect in Singapore, Malaysia and Hong Kong, a negative Tuesday effect in Thailand, and a positive Friday effect in the four markets. Wong and Yuanto (1999) found a significant negative effect on Tuesdays and a positive effect on Fridays in the daily returns of the Jakarta Composite Index (Indonesia) for the period 1983-1997.

Chusanachoti and Kamath (2002) investigated the Thailand stock market index for the period 1990-1998. The findings are similar to previous studies with respect to Monday, Tuesday and Friday, but they also found a negative effect on Thursday. Further, Oguzsoy and Guven (2003) examine the daily seasonal anomaly in this market for the period from January 1988 to November 1999 and find that the Turkish stock-market exhibits the significant negative effect on Monday and Tuesday and positive effect on Friday.

In China, Mookerjee and Yu (1999) document that a significant positive effect on Thursday and Friday is present in the Shanghai Securities Exchange, but the daily seasonal anomaly does not exist in the Shenzhen Securities Exchange for the period between April 1991 and April 1994. The Indian stock-market exhibits a positive effect on Friday (Choudhry, 2000). Selvakumar (2011), studied the day of the week effect in the Indian stock market for the period from 1992 to 2005 and the results for the period indicates that mean returns are negative for Monday, Tuesday and positive for Wednesday, Thursday and highest returns for Friday.

Finally, there are very few studies have been found on this issue for the Sri Lankan stock market. Fernando and Pathirawasam (2006) used the ordinary least square (OLS) equation to examine the day of the week effect in Colombo stock exchange for the period from 1985 to 
2004. They revealed that there is no any significant day of the week effect in the total period. Further, Thilakerathne et al., (2007) examined the presence of day of the week effect in the Colombo stock exchange with highest (positive) and lowest (negative) returns are observed on Fridays and Mondays respectively over 17 years period: 1st January 1994 through 31st March 2007. But there is no empirical evidence regarding the use of Generalized Autoregressive Conditional Heterocedadasticity $(\mathrm{GARCH})$ model apart from OLS model to examine day of the week effect for the Colombo Stock Exchange (CSE). OLS model ignores the time-varying volatility and can lead to wrong conclusions. GARCH model is considered to be a more appropriate model as it takes the time-varying volatility in to account. The present study attempts to utilize GARCH model to test the above hypothesis.

\section{Data and Methodology}

For this study, 10-year record of returns by day of the week using All Share Price Index (ASPI) is used. Furthermore, data is gathered from $1^{\text {st }}$ January 2001 to $31^{\text {st }}$ December 2011. Using ASPI data, for each day, a return is calculated as the percentage change in the value (2390 observations) of the index from preceding day. The following regression models are employed in the study to test the presence of a day of the week effect on stock returns in the Colombo Stock Exchange. Previous researchers have used both OLS method and GARCH method to test the same. However, it is evident that most of the recent studies on this phenomenon are mainly based on GARCH model as it eliminates some of the problems that OLS has.

The OLS model which is employed in this study is as follows.

(1) $R_{i t}=\alpha_{1} D_{1 t}+\alpha_{2} D_{2 t}+\alpha_{3} D_{3 t}+\alpha_{4} D_{4 t}+\alpha_{5} D_{5 t}+\varepsilon_{t}$

(2) $\varepsilon_{\mathrm{t}} \approx \mathrm{N}(0, \mathrm{ht})$

Where,

$\mathrm{R}_{\mathrm{it}}=$ the $\log$ return of the market index (ASPI);

$\mathrm{D}_{1 \mathrm{t}}=$ dummy variable for Monday $\left(\mathrm{D}_{1 \mathrm{t}}=1\right.$ if the observation is on Monday, otherwise 0$)$;

$D_{2 t}=$ dummy variable for Tuesday $\left(D_{2 t}=1\right.$ if the observation is on Tuesday, otherwise 0$)$;

$D_{3 t}=$ dummy variable for Wednesday $\left(D_{3 t}=1\right.$ if the observation is on Wednesday, otherwise $0)$; 
$D_{4 t}=$ dummy variable for Thursday $\left(D_{4 t}=1\right.$ if the observation is on Thursday, otherwise 0$)$;

$D_{5 t}=$ dummy variable for Friday $\left(D_{5 t}=1\right.$ if the observation is on Friday, otherwise 0$)$;

$\varepsilon_{\mathrm{t}}$ is an error term and assumed to be independently and identically distributed.

Empirical studies on this phenomenon suggest that the assumption of homoscedasticity is normally violated in the context of financial time series. Thus the above model will be tested for $\mathrm{RCH}$ effect. If the ARCH effect is present is the model, the following GARCH $(1,1)$ model which allows the conditional variance to be dependent upon earlier own lags is used.

(3) $R_{i t}=\alpha_{1} D_{1 t}+\alpha_{2} D_{2 t}+\alpha_{3} D_{3 t}+\alpha_{4} D_{4 t}+\alpha_{5} D_{5 t}+h_{t}($ Mean Equation) $\varepsilon_{\mathrm{t}} \approx \mathrm{N}\left(0, \mathrm{~h}_{\mathrm{t}}\right)$

(4) $\mathrm{h}_{\mathrm{t}}=\omega+\delta \mathrm{h}_{\mathrm{t}-1}+\gamma \varepsilon_{\mathrm{t}-1}^{2} \quad$ (Variance Equation)

The hypothesis that the day of the week effect is present in the stock returns in CSE is accepted if any coefficient is significant in OLS and GARCH $(1,1)$ models.

\section{Results and Discussion}

The Table 01 shows the results of the day of the week effect on returns in the Colombo Stock exchange. As per the OLS results, the average returns on Friday is significantly higher than other days of the week. In other words, the Friday effect is present in the ASPI. Moreover, results reveal that returns on Thursday and Wednesday are also significantly higher than Mondays and Tuesdays.

Table 1: OLS results

\begin{tabular}{|l|l|l|l|}
\hline Day of the week & Coefficient & t-value & $p$-value \\
\hline Monday & -0.0656 & -1.1124 & 0.2661 \\
\hline Tuesday & -0.1088 & -1.8708 & 0.0615 \\
\hline Wednesday & $0.1258 * *$ & 2.1311 & 0.0332 \\
\hline Thursday & $0.2068 *$ & 3.5365 & 0.0004 \\
\hline Friday & $0.3312 *$ & 5.5574 & 0.0000 \\
\hline
\end{tabular}




\section{Note: * significant at the $1 \%$ level \\ **significant at the $5 \%$ level}

The above conclusion is based on the OLS results. The main problem with OLS method is that it ignores the time-varying volatility (ARCH effect) of returns. It is expected that the ARCH effect is present in the market returns. If it is present GARCH $(1,1)$ model should be used to estimate the coefficients. ARCH effect is tested using the Lagrange Multiplier (LM) test using 5 five lags. The Table 02 presents the LM test results. The LM test suggests that the $\mathrm{ARCH}$ effect is present in the model. Further, it is significant at the $1 \%$ level.

\section{Table 2: LM test results}

\begin{tabular}{|c|c|c|c|}
\hline Variable & Coefficient & t-value & $p$-value \\
\hline Constant & 0.8971 & 6.1991 & 0.0000 \\
\hline$e_{t-1}^{2}$ & 0.1331 & 6.4970 & 0.0000 \\
\hline$e_{t-2}^{2}$ & 0.2942 & 14.2540 & 0.0000 \\
\hline$e_{t-3}^{2}$ & 0.0471 & 2.1950 & 0.0283 \\
\hline$e_{t-4}^{2}$ & -0.0538 & -2.6081 & 0.0092 \\
\hline$e_{t-5}^{2}$ & 0.0367 & 1.7923 & 0.0732 \\
\hline$F$-statistics & 69.3613 & $p$-value $(F)$ & 0.0000 \\
\hline Chi square-Statistics & 303.4454 & $\begin{array}{l}p \text {-value } \\
\text { (Chi } \\
\text { square) }\end{array}$ & 0.0000 \\
\hline
\end{tabular}

Since the ARCH effect is present in the OLS model, GARCH $(1,1)$ model is more appropriate than OLS model as it takes the time-varying variance into account. The results of the GARCH are given by the Table 03 . 
Table 3: GARCH model results

\begin{tabular}{|c|c|c|c|}
\hline & Coefficient & z-value & $p$-value \\
\hline \multicolumn{4}{|c|}{ Conditional Mean Equation } \\
\hline Monday & 0.0127 & 0.3986 & 0.6903 \\
\hline Tuesday & -0.0301 & -0.8515 & 0.3945 \\
\hline Wednesday & $0.1406 *$ & 3.9823 & 0.0001 \\
\hline Thursday & $0.2117 *$ & 5.6801 & 0.0000 \\
\hline Friday & $0.2217 *$ & 6.3840 & 0.0000 \\
\hline \multicolumn{4}{|c|}{ Conditional Variance Equation } \\
\hline$\omega$ & $0.0939 *$ & 12.3490 & 0.0000 \\
\hline$\varepsilon_{t-1}^{2}$ & $0.3304 *$ & 18.1962 & 0.0000 \\
\hline$h_{t-1}$ & $0.6535 *$ & 52.9521 & 0.0000 \\
\hline
\end{tabular}

Note:* significant at $1 \%$ level

Results obtained from the GARCH model suggest that Friday effect in the stock returns is significant at $1 \%$ level. In addition to this effect, Thursday effect in stock returns is also significant at $1 \%$ level. Moreover, Wednesday returns are also significant at $1 \%$ level. Therefore, there is sufficient evidence to conclude that the Friday effect, Thursday effect and Wednesday effect in the stock returns of the Colombo Stock Exchange are present.

In conclusion, the day of the week effect is present in the return in Colombo Stock Exchange. Moreover, sufficient evidence is found to support the hypothesis of the day of the week effect in stock returns in the Colombo Stock Exchange. Due to this day of the week effect, investors can earn an abnormal return by buying stocks on Mondays and Tuesdays and selling stocks on Wednesdays, Thursdays and Fridays. Further it can be concluded that Colombo Stock Exchange is not weak form efficient as investors can earn abnormal returns by trading on strategy based on past information. 


\section{References}

Balaban, Ercan, Asli Bayar and OzgurBerk Kan. (2001).Stock return seasonality and asymmetric conditional volatility in World equity markets.Applied Economics Letters, 8(4), 263-268.

Balbina M. and Martins N.C.(2002). The analysis of seasonal returns anomalies in the Portuguese stock market. (online) available,

http://www.bportugal.pt/en-US/BdP\%20Publications\%20Research/WP200211.pdf

Banz,R.W.(1981).The Relationship Between Return and Market Value of Common Stock. Journal of Financial Economics 9(1),3-18.

Bepari K. and Mollik A.T. (2009).Seasonalities in the Monthly stock returns: Evidence from Bangladesh Dhaka Stock Exchange. International Research Journal of Finance and Economics,24(2),167-176.

Berument H. and Kiymaz H.(2001). The day of the week effect on stock market volatility.Journal of Economics and Financa, 25(2), 181-190.

Choudhry, Taufiq. (2000). Day of the Week Effect in Emerging Asian Stock Markets: Evidence from the GARCH Model. Applied Financial Economics, 10(3), 235-242.

Chusanachoti, Jirayuth and RavindraKamath., (2002). Market conditions, return distributions, and the day of the week effects in Thailand: The experience of the 1990s. American Business Review, 20(1), 6-14.

D.S.selvakumar.(2011). Existence of Certain Anomalies In Indian Stock Market, Proceedings of International Conference on Economic and Finance Research (pp 498-504). School of social science VIT university.

Dubois, M. and Louvet, P. (1996). The day of the week effect: the international evidence. Journal of Banking and Finance, 20(9),1463-84.

Fama, E.F.(1991). Efficient Capital Markets.Journal of Finance,46(5),1575-1617. 
Fernando P.N.D. and Pathirawasam C. (2006). An empirical study on the week effect ; Evidence from Colombo Stock Exchange. Proceedings of the Annual Research Symposium 2006 (pp 103), University of Kelaniya, Sri Lanka.

French K.R. (1980).Stock returns and the weekend effect.Journal of financial economics, $8(2), 55-69$.

Jaffe, J. y R. Westerfield (1985). The week-end effect in common stock returns: The international evidence. Journal of Finance, 40(2),433-454.

Kohers, G., Kohers, N., Pandey, V., Kohers, T.(2004). The disappearing day-of-the-week effect in the world's largest equity markets.Applied Economics Letters, 11(3),167-171.

Mookerjee, Rajen and Qiao Yu. (1999). An Empirical Analysis of the Equity Markets in China. Review of Financial Economics, 8(1),41-60.

Oguzsoy, CemalBerk and SibelGuven, (2003), Stock Returns and the Day-of-the-week Effect in Istanbul Stock Exchange, Applied Economics, 35(8),959-971.

PhilpottM.F, and Firer C. (1995). Share price anomalies and the efficiency of the JSE. Investment analysts journal,40 (summer),39-51.

Rosa MaríaCáceresApolinario, Octavio Maroto Santana, Lourdes Jordán Salesand Alejandro Rodríguez Caro.(2006). "Day of the Week Effect on European Stock Markets".International Research Journal of Finance and Economics, 1(2),53-69.

Thilakerathne P.M.C., Amarasiri K.P.M.M, and Abeywardena D.K.Y.(2007).Seasonality Effect of Emerging Stock Markets: Evidence from Sri Lanka,Proceedings of the $11^{\text {th }}$ International Conference on Sri Lanka Studies ( $p p$ 15), University of Kelaniya, Sri Lanka.

Sehgal S. and Tripathi V. (2005).SizeEffectin Indian Stock Market: Some Empirical Evidence. Journal of Business Perspective,9(4),27-42.

Syed A. Basher and Perry Sadorsky. (2006). Day-of-the-week effects in emerging stock markets..Applied Economics Letters, 13(10), 621-628. 
Truong Dong Loc.(2012). Day-of-the-week effect on stock returns and volatility: The case of Ho Chi Minh Stock Exchange, Vietnam. Asian Journal of Management Research,2(1),711-721.

Wong, Kie Ann, TakKeeHui and Choy Yin Chan.(1992). Day of the week effect: The evidence from developing stock markets. Applied Financial Economics, 2(1),49-56.

Wong, K., and K.Yuanto.(1999). Short-term seasonalities on the Jakarta stock exchange.Review of Pacific Basin Financial Markets and Policies, 2(3), 375-398. 